\title{
SELECTED PROPERTIES OF CONCRETE CONTAINING MUNICIPAL SOLID WASTE INCINERATION BOTTOM ASH (MSWI-BA)
}

\author{
Meheddene Machaka ${ }^{1 a}$, Jamal Khatib ${ }^{1 b}$, Adel Elkordii ${ }^{1 c}$, \\ Hassan Ghanem ${ }^{1 d}$, Oussama Baalbaki ${ }^{1 \mathrm{e}}$ \\ ${ }^{I}$ Beirut Arab University, Department of civil and environmental engineering, Beirut, \\ Lebanon. \\ ${ }^{1 a}$ Email: <m.mashaka@bau.edu.lb>; ${ }^{1 b}$ Email: j.khatib@bau.edu.lb; \\ ${ }^{1 c}$ Email: a.elkordi@bau.edu.lb; ${ }^{l d}$ Email: <h.ghanem@bau.edu.lb>; \\ ${ }^{1 e}$ Email: 〈obaalbaki@bau.edu.lb>.
}

\begin{abstract}
Nowadays, remarkable achievements towards the sustainability of our environment. These include the use of recyclable materials to improve the greenness of the concrete by incorporating them in the concrete industry. One of the main concerns for researchers when using new material in concrete is its engineering and durability properties. This study was conducted to investigate the mechanical properties and the durability of concrete when using Municipal Solid Waste Incineration Bottom Ash (MSWIBA) as a replacement for fine aggregate to produce green and sustainable concrete. Two percentages for sand replacement $25 \%$ and $50 \%$ were used to evaluate the effect of incorporating this material on the concrete compressive strength, density, UPV, total water absorption, and capillary water absorption properties. The water to cement ratio used was 0.45 , and the specimens were tested at 7,14, and 28 days. A comparison for the results of concrete specimens with and without MSWI-BA was performed. The results showed that replacing 25\% of sand with MSWI-BA has no harmful effect on the compressive strength of the concrete that encourages this strategy. However, using higher replacement percentage 50\% decreases sharply the strengths to about $50 \%$. On the other hand, water absorption by total immersion and by capillary increased when replacing sand was with $25 \%$ and $50 \%$ MSWI-BA. In summary, using $25 \%$ of MSWI-BA as sand replacement is an effective strategy to produce eco-friendly concrete in that it would produce concrete material that has less embodied energy to produce.
\end{abstract}

Keywords: Absorption, Concrete, Capillarity, Municipal Solid Waste Incineration Bottom Ash, Sustainability, Waste. 


\section{INTRODUCTION}

Sustainable development is a goal that most nations in the world are striving towards. Reusing and recycling will be a key to achieving this goal. Central to this is the utilization of waste products in construction activities. For example, recycled and waste materials can be used to replace either the aggregate or cement in the production of concrete [Black 2016, El-Darwish et al. 1997, Hadjsadok et al. 2012, Herki and Khatib 2016, Khatib 2009, Khatib 2014, Khatib et al. 2006, Khatib et al. 2008, Khatib et al 2013a, Khatib et al. 2013b, Khatib et al. 2014, Khatib et al. 2016, Kurdi et al. 1996, Menadi et al. 2014, Morales-Hernandez et al. 2005, Owens et al. 2016, Wright et al. 2016, Zhansaya 2014].

In Lebanon, one of the big problems that facing the country is Municipal Solid Waste that results up mainly from residential apartments. These solid wastes form a major harmful problem that affect the Lebanese society and global in general. Municipal solid waste can be used to generate energy. Several technologies have been developed that make the processing of MSW for energy generation cleaner and more economical than ever before [Dovi 2009]. One of the most common solution of these Municipal Solid Waste is by incinerating it and reuse it in construction products or materials as sand replacement in the concrete production depending on the size of granules resulted from the incineration tank that contains bottom and fly ashes. These ashes could be potentially used in concrete, road pavements, embankments, ceramics, and glasses. MSWI bottom ash if treated appropriately has no negative or harmful effect on humans or life beings so we can use it in any space of work. Thus, using MSWI bottom ash in construction helps in one way to reduce pollution problem and in other way can help in saving materials and money for construction [Liu 2015]. In addition, Using the waste material from the Incineration plants in concrete production will open new market opportunities in sustainability development [Nikbin 2016].

Li et al. [Li 2016] showed that the technology of MSWI is playing an important role around the world nowadays and continue in growing, for example in china the number of plants that uses the incineration technology increased from 69 plants in year 2006 to 188 plants in 2014 providing a huge amount of bottom ash as a waste material was produced that is cheap and can be used in construction field. In fourteen European countries there are more than 200 waste-to-energy plants in 2006 and the number in increase, these plants managing about 23\% of MSW of these countries. In US more than 89 waste-to energy plants operating in 27 states [Ornebjerg et al. 2006]. One of the main concerns is the effect of using these materials on the mechanical properties and durability of the concrete. Many researchers in several countries investigate these effects. A study carried out by M. Salvo et. al in 2015 used ashes from three different power plants in Sweden declared that one of these products may successfully could be used as a supplementary cementing material that result a concrete with properties close to that with ground granulated slag [Salvo 2015]. Another study observed that concrete strength improved significantly when replacing $30 \%$ of Portland cement with MSWIBA and the permeability of the concrete decreases [Bertolini 2005]. Aggarwal \& 
Gupta in 2007 investigate the effect of replacing from $0 \%$ to $50 \%$ of fine aggregate by MSWI-BA on the workability, compressive, flexural, and splitting tensile strength of concrete. The results showed decrease in the workability with the increase of BA percentage, decrease in strengths at 28 days, however strength gain continue to 91 days where concrete strength reach more than $90 \%$ control mix and more than $110 \%$ compared to 28 days of control mix. In summary, strength of concrete is acceptable for most structural concrete applications since it is compressive strength more than 20 Mpa at 28 days [Aggarwal 2007]. Finally, using MSWI-BA as a partial replacement to fine aggregate in concrete from $10 \%$ to $50 \%$ decrease density from $93 \%$ to $89 \%$, compressive strength from $96 \%$ to $43 \%$, and an increase in the absorption capacity especially for a replacement higher than 30\% [Tang 2017].

The aim of this study is to investigate the effect of adding MSWI-BA to concrete as a partial replacement to sand on the concrete properties. The water cement ratio used in this study is 0.45 . Two partial replacement for sand are used in this study; for that three mixes were prepared, the first one without bottom ash as a control mix; the used replacements are $25 \%$ and $50 \%$. To evaluate the effect of replacement, five tests for concrete properties at 7,14, and 28 days were applied. The test investigated are density, UPV, Compressive strength, Total water absorption, and finally capillary water absorption.

\section{MATERIALS AND MIX PROPORTIONS}

\section{Materials}

Natural sand and coarse aggregate from the mountain of Lebanon was used as aggregate. Both aggregates were sieved and graded according to the ASTM C33 and C136 requirements. The physical properties for fine and coarse aggregates are shown in Table 1. The cement used is PA-L 42.5, Conforms to EN 197 European norms (CEM II/A-L) and to Lebanese standards (LIBNOR). MSWI-BA was obtained from an incineration plant located in the Bekaa Valley and was oven dried at $100 \mathrm{C}$ for 24 hours before use in the concrete mix.

Table 1. Coarse and Fine Aggregates' Properties

\begin{tabular}{|c|c|c|c|c|}
\hline Aggregate & Type & S.G. & Absorption \% & FM \\
\hline Fine Aggregate & Natural sand & 2.51 & $1.56 \%$ & 2.7 \\
\hline Coarse Aggregate & Crushed stone & 2.60 & $1.35 \%$ & \\
\hline
\end{tabular}

\section{Mix Proportions}

Three Concrete mixes were prepared to study the effect of using Municipal Solid Waste Incineration Bottom Ash (MSWIBA) as replacement of fine aggregate on the compressive strength, density, UPV, total and capillary water absorption. The replacement of fine aggregate was 0,25 and $50 \%$ for mixes M1, M2 and M3 respectively.

Table 2. Detail of Mixes (weights in $\mathrm{Kg}$ )

\begin{tabular}{|c|c|c|c|c|c|c|}
\hline Mix & $\%$ of BA & Cement & Water & Sand & C.A & B.A \\
\hline Mix 1 & $0 \%$ & 460 & 234 & 900.5 & 1065 & 0 \\
\hline
\end{tabular}




\begin{tabular}{|c|c|c|c|c|c|c|}
\hline Mix 2 & $25 \%$ & 460 & 242 & 675.5 & 1065 & 225 \\
\hline Mix 3 & $50 \%$ & 460 & 247.5 & 450 & 1065 & 450 \\
\hline
\end{tabular}

\section{EXPERIMENTAL PROGRAM}

\section{Durability Study}

Permeability of concrete represent the capacity of water to penetrate the concrete which is mainly related to the concrete durability. High permeability reduces the durability of the concrete where it allows harmful materials to penetrate the concrete that react and destroy its chemical stability [Khatib 1998]. Moreover, low permeability of concrete can improve resistance to the penetration of water, sulphate ions, chloride ions, alkali ions, and other harmful substances which caused chemical attack [Alhozaimy 1996]. Permeability can be evaluated and represented using total water absorption test, capillary water absorption test and sorptivity test [Tasdemir 2003]. Martys and Ferraris have shown that improving the sorptivity coefficient may improve the concrete performance and durability and it is essential to predict the service life of concrete [Martys 1997]. To explain, sorptivity is an index of moisture transport in to unsaturated specimens, and recently it has also been recognized as an important index of concrete durability [Rehman 2016].

\section{Specimen Preparation and Curing Conditions}

All specimens were prepared in the Beirut Arab University construction material lab. Cubes of dimension $100 * 100 * 100 \mathrm{~mm}$ are use in this investigation for all tests. Specimens were demolded and cured in water at the room temperature to the date of testing.

\section{Test Methods}

For the compressive strength tests, The Universal crushing machine was used in the compression strength test according to ASTM C 31, C 39, C 192, \& C 617. For the density of fresh concrete, the ASTM C138 was applied to determine the fresh unit weight of the concrete after mixing. For the UPV, Ultrasonic pulse velocity testing of concrete is based on the pulse velocity method to provide information on the uniformity of concrete, cavities, cracks and defects, presence of voids, honeycombing or other discontinuities. Table 3 shows the guidelines for qualitative assessment of concrete based on UPV test results [ASTM 2012, ASTM 2013, ASTM 2016].

Table 3. Quality of Concrete Based on UPV Value

\begin{tabular}{|c|c|}
\hline Pulse Velocity & Concrete Quality \\
\hline$>4.0 \mathrm{~km} / \mathrm{s}$ & Very good to excellent \\
\hline $3.5-4.0 \mathrm{~km} / \mathrm{s}$ & Good to very good, slight porosity may exist \\
\hline $3.0-3.5 \mathrm{~km} / \mathrm{s}$ & Satisfactory but loss of integrity is suspected \\
\hline$<3.0 \mathrm{~km} / \mathrm{s}$ & Poor and loss of integrity exist. \\
\hline
\end{tabular}

For the total water absorption test, the specimens were casted, demolded, and then cured in water at room temperature to the date of testing. In the days of testing, specimens were removed from water, dried in the oven for 48 hours at $80^{\circ}$ until specimens reach a constant weight. At this time, the weight registered as dry weight 
assigned by $\mathbf{A}$ (dry weight). After that, the specimens have been immersed totally in the water for 5 minutes then removed, wiped with a towel to remove any excess water at the concrete surface. At this point, the specimen weight is registered to get the first reading at 5 minutes assigned by $\mathbf{B}$ (wet weight) then the specimens were re-immersed in water directly and the procedure are repeated at $10 \mathrm{~min}, 20 \mathrm{~min}, 60 \mathrm{~min}, 120 \mathrm{~min}$, $240 \mathrm{~min}, 1$ day, and finally 2 days. The increase in the weight of the specimens at different time intervals indicates water absorption represented by the percentage of total water absorption $=(\mathbf{B}-\mathbf{A}) / \mathbf{A} * \mathbf{1 0 0}$.

For the capillary water absorption, cubes $100 * 100 * 100$ were used in this test. The cubes cured for the same ages as before then dried. On the other hand, after removing the specimen from the oven, the cubes were sealed at their four sides to prevent absorption other from the bottom sides that is in contact with water as shown in Figure 1. The sealing was higher 3 to $5 \mathrm{~mm}$ from the bottom as ASTM C1585 specify. Weight of the specimen was recorded and assigned as W1 (dry weight). The specimens were put in a bottle filled with water to cover the concrete sides from 3 to $5 \mathrm{~mm}$ as shown in figure. After 1 minute from immersion, the cubes were removed, wiped, and weighted to record the first weight at 1 minute with water absorbed by capillarity and assigned as W2. The procedure repeated at minutes 3,5,10,30,60, then 1 day, and finally 2 days. From these results, the capillary water absorption at each reading was obtained by dividing the cumulative water absorption over the surface area of the cube through which water penetrates as shown in the following relationship:

$I(\mathrm{~mm})=\frac{\Delta \mathrm{W}}{\mathrm{A} . \mathrm{d}}=\frac{\mathrm{W}_{2}-\mathrm{W}_{1} \text { (in grams) }}{\text { A.d }}$ where,

$A=$ surface area of the cube through which water penetrates $\left(\mathrm{mm}^{2}\right)$

$\mathrm{d}=$ density of water $\left(\mathrm{g} / \mathrm{mm}^{3}\right)$

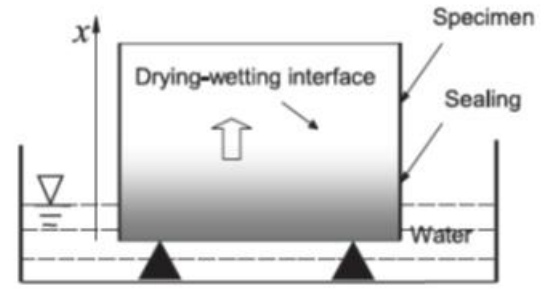

Figure 1. The Schematic Diagram of Capillary Absorption

To determine the sorptivity, using strategies from ASTM 1585, Standard Test Method for Measurement of Rate of Absorption of Water by Hydraulic-Cement Concretes, this test method is used to determine the rate of absorption (sorptivity) of water in hydraulic cement concrete by measuring the increase in the mass of a specimen resulting from absorption of water as a function of time when only one surface of the specimen is exposed to water. The sorptivity that was obtained is the initial slope for the curve between I the cumulative absorbed volume of water per unit area of inflow surface and the square root of time in minutes. In short, sorptivity is based on the rate of absorption, which is proportional to the surface area exposed to moisture and time. The sorptivity can be calculated from the following relationship: 


$$
\mathrm{I}=\mathrm{S} \cdot \sqrt{\mathrm{t}} \text { where, }
$$

$\mathrm{I}=$ the cumulative water absorption over the surface area in $\mathrm{mm}$.

$\mathrm{t}=$ time of taking the weight in minutes.

$\mathrm{S}=$ sorptivity in $\mathrm{mm} / \sqrt{t}$

\section{RESULTS AND DISCUSSION}

\section{Compressive Strength}

The compressive strength results are shown in Figure 2 At 7days, the concrete strengths were $32.3 \mathrm{MPa}, 33.41 \mathrm{MPa}, 19.2 \mathrm{MPa}$ for $0 \%, 25 \%$, and 50\% of MSWI-BA fine aggregate replacement respectively. The results show that replacing $25 \%$ of fine aggregate with Bottom Ash maintain the concrete strength with a slight increase about $1 \%$. In contrary, replacing 50\% decreases sharply the concrete strength. The decrease in the concrete compressive strength at 7 days was about $40 \%$.

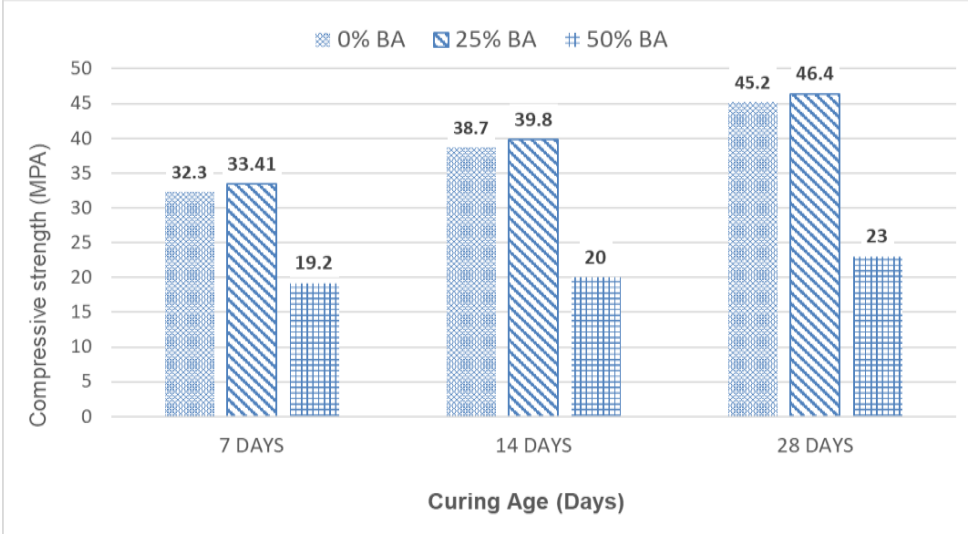

Figure 2. The Effect of Using MSWI-BA on the Concrete Compressive Strength at 7,14 , and 28 Days of Curing

The results showed the same behavior at 14 and 28 days. As shown in figure, the compressive strength at 28 days were 45.2 $\mathrm{MPa}, 46.4 \mathrm{MPa}$, and $23 \mathrm{MPa}$ for $0 \%, 25 \%$, and $50 \%$ of MSWI-BA replacement respectively. The decrease in strength at 28 days was $50 \%$ for $50 \%$ MSWI-BA replacement. In addition, the gaining in strength from 7 to 28 days also was affected by the MSWI-BA percentage of replacement. The percentages of strength increase from day 7 to day 28 were $40 \%, 39 \%$, and $20 \%$ for $0 \%, 25 \%$, and $50 \%$ of MSWI-BA fine aggregate replacement respectively. The results showed that using the percentage of $50 \%$ in the fine aggregate replacement with MSWI-BA reduces the gain of strength at 28 days to $50 \%$. In summary, using $25 \%$ of MSWI-BA as partial replacement of fine aggregate maintain the concrete strength and strength gain at 28 days.

\section{Density}

The density of bottom ash is lower than that of natural sand. For that, as many researchers reported when using bottom ash as partial replacement for fine aggregate, using MSWI-BA as partial replacement of sand decrease the density of the concrete. 
Figure 3 shows the results for the concrete density for $0,25 \%$ and $50 \%$ of BA replacement at 7,14, and 28 days of curing. The densities of concrete are $2364 \mathrm{Kg} / \mathrm{m}^{3}$, $2315 \mathrm{Kg} / \mathrm{m}^{3}$, and $2269 \mathrm{Kg} / \mathrm{m}^{3}$ for 0, 25\%, 50\% MSWI-BA replacement after 28 days of curing in water respectively. As shown in figure, when using $25 \%$ and $50 \%$ of sand were replaced with BA, the density of the concrete decreased $2 \%$ and $4 \%$ respectively for the results obtained at 28 days.

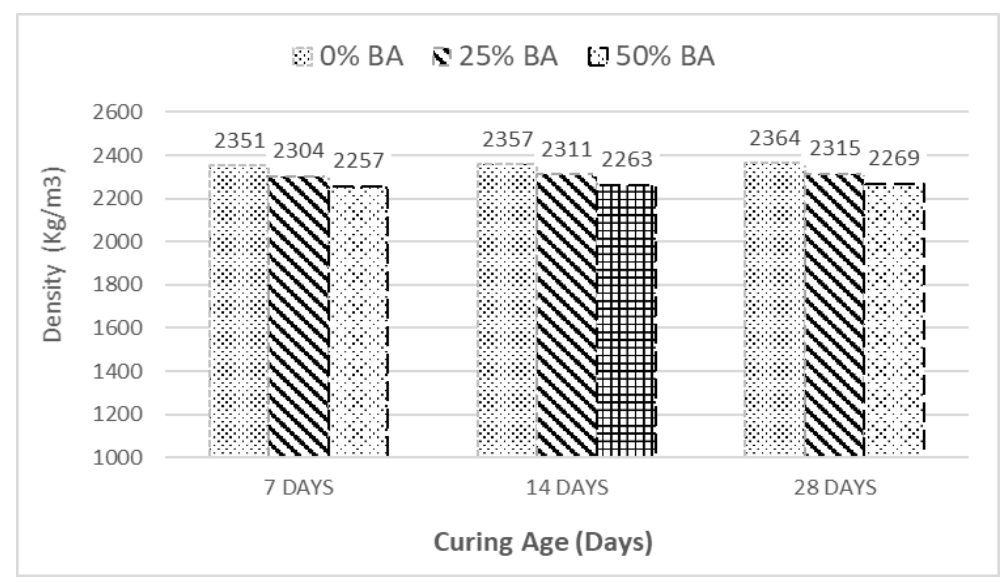

Figure 3. The Effect of Using MSWI-BA on the Density at 7,14, and 28 Days.

Ultra Pulse Velocity (UPV). The effect of fine aggregate replacement with bottom ash in concrete mix on the pulse velocity was shown in Figure 4. The results of UPV tests are $3.84,3.1,2.49 \mathrm{Km} / \mathrm{s}$ at 7 days: $3.86,3.16,2.54 \mathrm{Km} / \mathrm{s}$ at 14 days: $3.78,2.94$, $2.42 \mathrm{Km} / \mathrm{s}$ at 28 days for MSWI-BA replacement of $0,25 \%$, and $50 \%$ respectively. According to Table 3 for the quality of concrete based on UPV value, using $25 \%$ of BA result satisfactory quality of concrete. Although, using $50 \%$ of BA result poor concrete quality and loss of integrity in the new product.

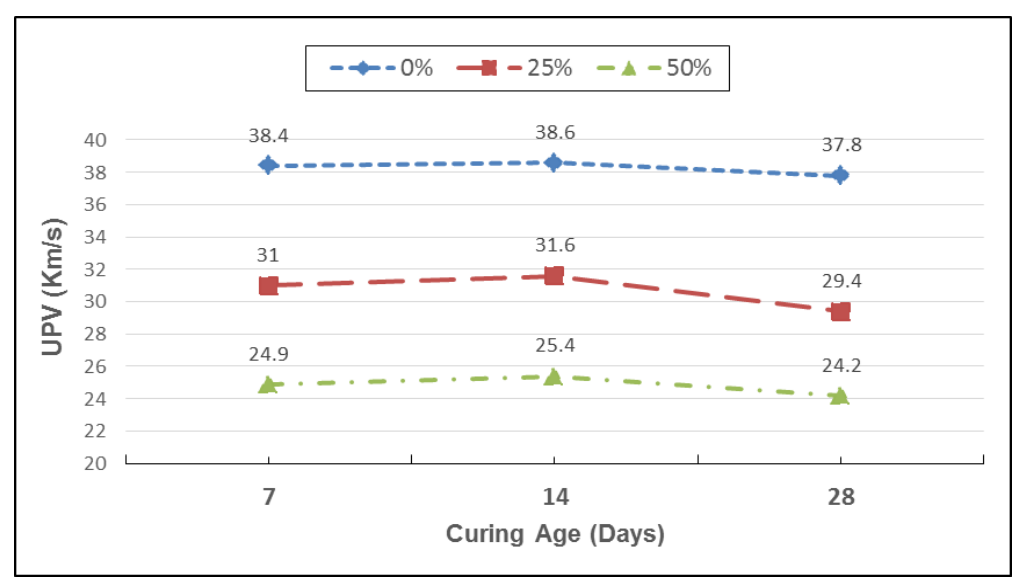

Figure 4. UPV Results for Different Concrete Mixes at 7,14, and 28 Days 


\section{Total Water Absorption}

Figure 6 shows the average of the total water absorption for the concrete specimens after 28 days of curing for different mixes depending on the percentage of Bottom ash replacements. The specimens were totally immersed in water for 48 hours and the readings recorded at time intervals as specified previously. The results show that replacing sand with bottom ash in the concrete mix increases the rate of total absorption with time. At square root of time in sec for number 60 (at time 60 minutes), the percentages of absorption were $1.14 \%, 1.25 \%$, and $1.42 \%$ for the concrete specimens with $0 \%$ (control), $25 \%$, and $50 \%$ of MSWI-BA replacement respectively. It was noted the replacing $25 \%$ and $50 \%$ of sand with BA increases the total water absorption to approximately $10 \%$ and $25 \%$ respectively for absorbed water after one hour of water immersion for concrete cured 28 days in water.After 48 hours of immersion in water $(\sqrt{t}=415.7)$, replacing $0 \%, 25 \%$ and $50 \%$ of sand with BA recorded for 14 days of curing age $2.87 \%, 3.07 \%$, and $3.36 \%$ for the total water absorption respectively as shown in Figure 7.

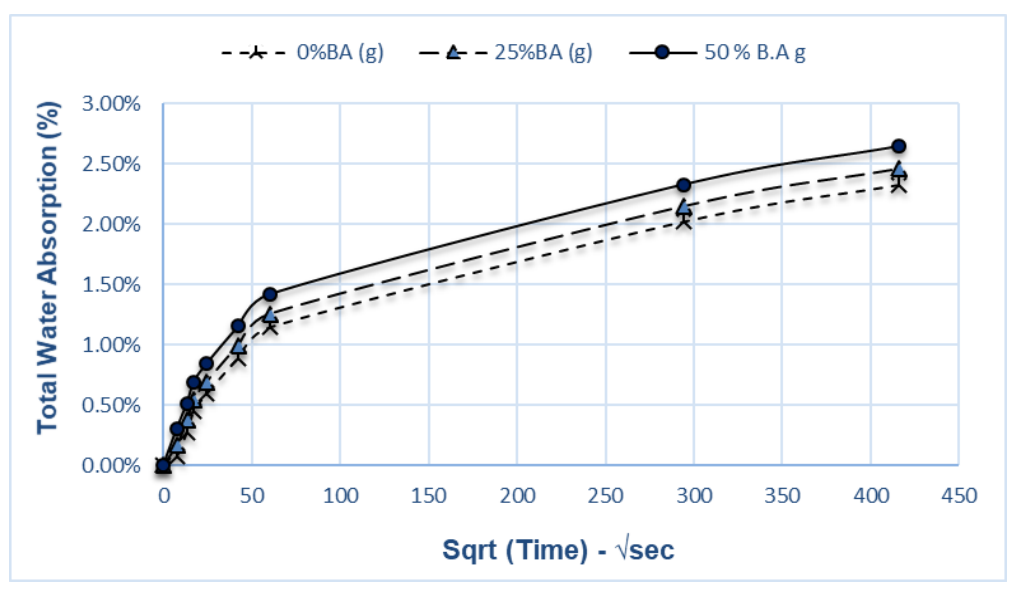

Figure 6. The Effect of Using BA on the Total Water Absorption After 28 Days

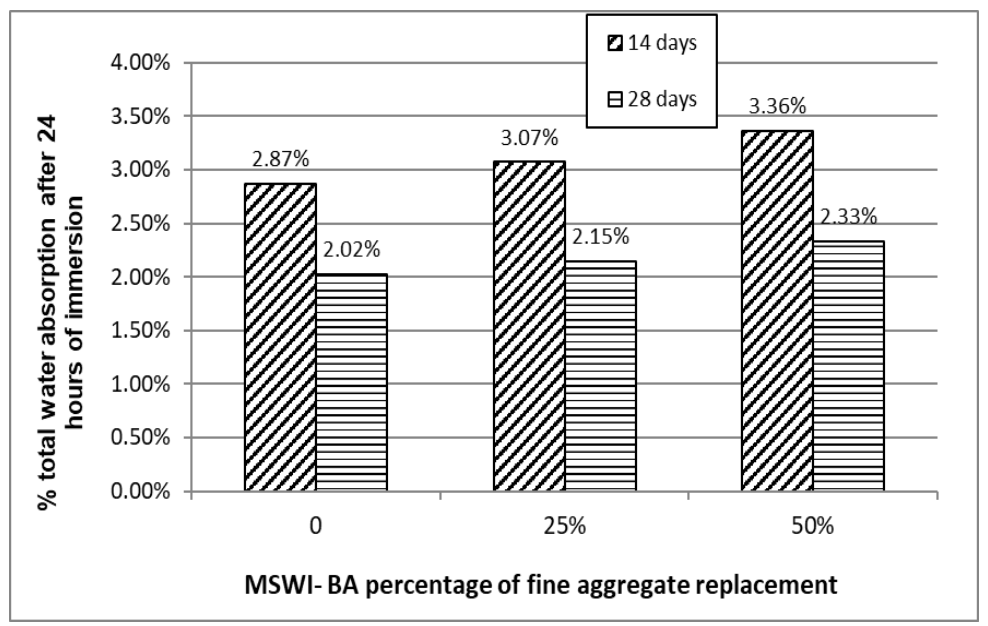

Figure 7. The Effect of Using BA on the Total Water Absorption of Concrete 
For 28 days of curing, the total water absorptions are $2.02 \%, 2.15 \%$, and $2.33 \%$ respectively. Consequently, the Increase in the percentage of total water absorption to about $6 \%$ when replacing $25 \%$ of sand with BA decreases slightly the durability of the concrete.

\section{Capillary Water Absorption \& Sorptivity}

Figure 8 Shows the curve recorded from the capillary water absorption at different time intervals until 48 hours with the square root of time in seconds after 28 days of curing. The capillary water absorption records are $0.404,0.428$, and $0.459 \mathrm{~mm}$ for mixes with $0 \%, 25 \%$, and $50 \%$ of BA replacement respectively. Adding $25 \%$ and $50 \%$ MSWI-BA as a replacement of natural sand increase the capillarity of the concrete $9 \%$ and $12 \%$ respectively.

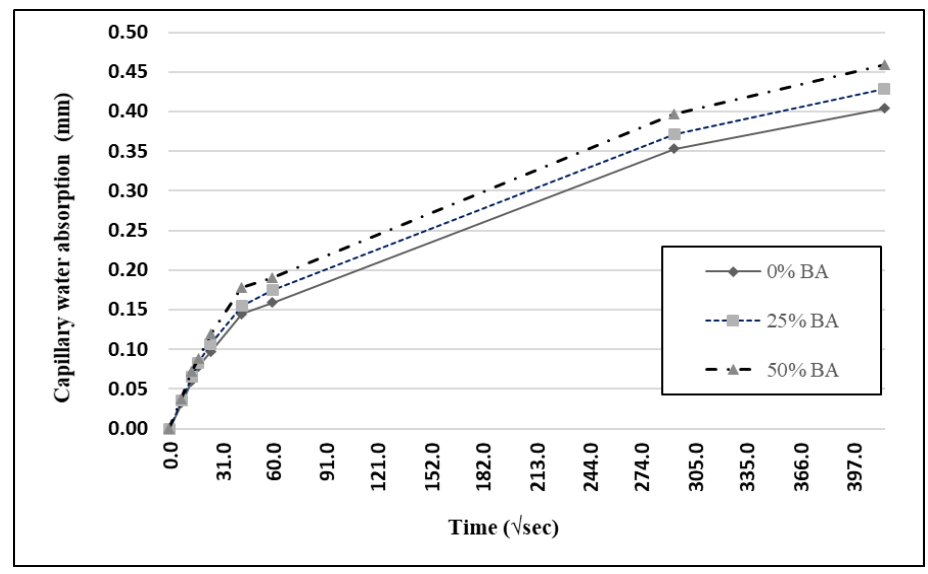

Figure 8. The Effect of BA on the Capillary Water Absorption After 28 Days

Figure 9 shows the slope of the capillary water absorption for the first 60 minutes that represent the sorptivity. The results are recorded and plotted for two curing ages 14 and 28 days. The results show that the sorptivity slightly decreased with time with curing for the control mix ( $0 \% \mathrm{BA})$ and when replacing $25 \%$ of sand with BA, but for $50 \%$ BA replacement the sorptivity increased $20 \%$. 


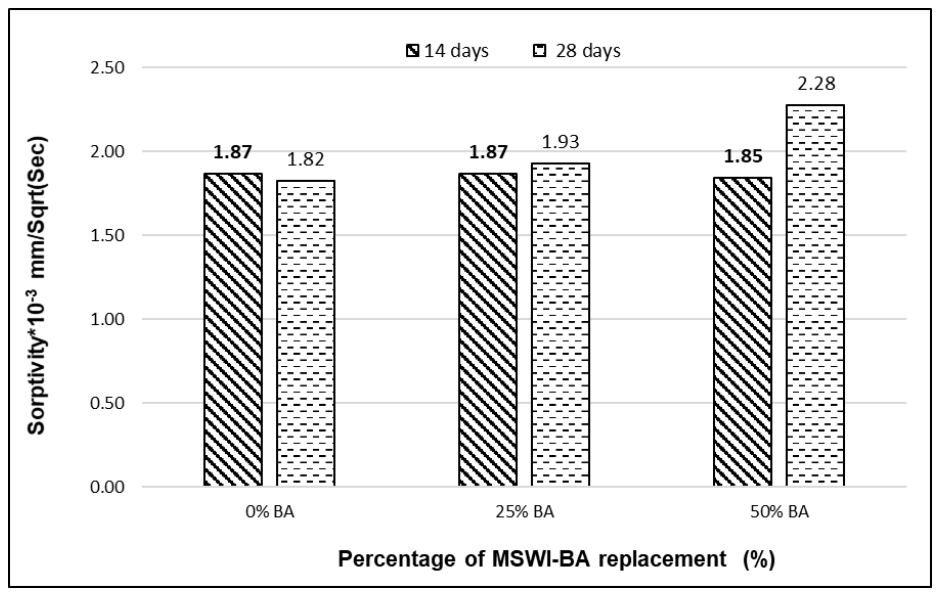

Figure 9. Sorptivity Results After 14 and 28 Days of Curing.

The sorptivity recorded are $1.87,187$, and $1.85 \mathrm{~mm} / \mathrm{Sqrt}(\mathrm{sec})$ after 14 days of curing for mixes with $0 \%, 25 \%$, and 50\% of MSWI-BA partial sand replacement respectively. After 28 days, the sorptivity results are 1.82, 1.93, and $2.28 \mathrm{~mm} / \mathrm{Sqrt}(\mathrm{sec})$ as shown in figure. The results show that replacing $25 \%$ of sand with BA slightly increases the sorptivity about $6 \%$, where using $50 \%$ of BA increased the sorptivity $25 \%$.

\section{CONCLUSION AND RECOMMANDATIONS}

The Experimental program applied in this research to investigate the effect of using MSWI-bottom ash from Lebanese incineration plant as partial replacement for fine aggregate on a series of concrete properties. Compressive strength, density, UPV, total water absorption, and capillarity of concrete with $25 \%$ and $50 \%$ of BA replacement were investigated and compared to the control mix. Based on the experimental results obtained, replacement of $25 \%$ of fine aggregate with BA maintain the compressive strength of concrete at 7, 14, and 28 days, where the strength decreased to about $50 \%$ at 28 days when using $50 \%$ BA. The density slightly reduced to about $2 \%$ and $4 \%$ for $25 \%$ and $50 \%$ partial replacement respectively. In addition, the UPV decreased $21 \%$ for $25 \%$ replacement even that the classification of concrete stay in the satisfactory classification but decreases to $36 \%$ for $50 \%$ replacement and classified as poor concrete. Absorption increased about $6 \%$ and $15 \%$ for the $25 \%$ and $50 \%$ replacement. Consequently, sorptivity increased about $6 \%$ and $25 \%$ for the $25 \%$ and $50 \%$ replacement after 28 days of specimens curing. In summary, replacing $25 \%$ of fine aggregate with BA is an encouraging strategy that reduce the landfill materials and the fine aggregate consumption to produce more ecofriendly concrete taking into consideration that replacing 50\% BA resulted serious reduction in most of the concrete properties.

For further researches, it is recommended to investigate other percentage replacements such as 20,25,30, and $35 \%$. In addition, mix design could be adjusted to 
improve the absorption and sorptivity by reducing the water cement ratio. More durability tests should be applied to evaluate the new product.

\section{REFERENCES}

Aggarwal, P., Aggarwal, Y. and Gupta, S.M. (2007). "Effect of bottom ash as replacement of fine aggregates in concrete." Asian Journal of Civil Engineering (Building and Housing) 8(1). 49-62.

Alhozaimy, A., Soroushian, P. and Mirza, F. (1996). "Effects of curing conditions and age on chloride permeability of fly ash mortar." Materials Journal, 93(1), 87-95.

ASTM C39/C39M (2012). "Standard Test Method for Compressive Strength of Cylindrical Concrete Specimens" ASTM International, West Conshohocken, PA.

ASTM C597 (2016). "Standard Test Method for Pulse Velocity through Concrete" ASTM International, West Conshohocken, PA.

ASTM C642 (2013). "Standard Test Method for Density, Absorption, and Voids in Hardened Concrete" ASTM International, West Conshohocken, PA.

ASTM C1585 (2013). "Standard Test Method for Measurement of Rate of Absorption of Water by Hydraulic-Cement Concretes" ASTM International, West Conshohocken, PA.

ASTM C1585 (2013). "Standard test method for measurement of rate of absorption of water by hydraulic cement concrete". ASTM International, West Conshohocken, PA.

Bertolini, L., Carsana, M., Cassago, D., Collepardi, M. and Curzio, A.Q. (2005). "Bottom ash of municipal solid wastes from incineration plant as mineral additions in concrete." International Concrete Research \& Information Portal, 229, pp.467-476.

Black, L. (2016). "Low clinker cement as a sustainable construction material." In: Khatib, J.M. (ed.), Sustainability of Construction Materials. 2nd edition. Elsevier, pp. 417460, ISBN 978-0-08-100995-6

Dovì, V.G., Friedler, F., Huisingh, D. and Klemeš, J.J. (2009). "Cleaner energy for sustainable future.” Journal of Cleaner Production, 17(10), pp.889-895.

El-Darwish, I.; Kurdi, A.; Mahmoud, H.; and Abou El-Kair, H. (1997) Mechanical Properties and Durability of Portland Cement Concrete Incorporating ground Steel Making Slag", Alexandria Engineering Journal, 36 (1), 1-14, January

Hadjsadok, A., Kenai, S., Courard, L., Michel, F., and Khatib, J.M. (2012) Durability of mortar and concretes containing slag with low hydraulic activity. Journal of Cement and Concrete Composites, 34 (5), 671-677, May 2012, ISSN 0958-9465. doi:10.1016/j.cemconcomp.2012.02.011

Herki, B.A. and Khatib, J.M. (2016) Valorisation of waste expanded polystyrene in concrete using a novel recycling technique. European Journal of Environmental and Civil Engineering, Taylor \& Francis pub, ttp://dx.doi.org/10.1080/19648189.2016.1170729

Khatib, J.M. (2009) Low curing Temperature of Metakaolin Concrete. American Society of Civil Engineers (ASCE) - Materials in Civil Engineering Journal, 21 (8), 362-367, August, ISSN 0899-1561/2009/8-362-367 DOI: 10.1061/(ASCE)08991561(2009)21:8(362)

Khatib, J.M. (2014) Effect of initial curing on absorption and pore size distribution of paste and concrete containing slag. Korean Society of Civil Engineers (KSCE) Journal, 18 (1), 264-272, January. pISSN 1226-7988, DOI 10.1007/s12205-014-0449-7

Khatib, J.M. and Wild, S. (1998) "Sulphate resistance of metakaolin mortar." Cement and Concrete Research Journal, 28 (1), 83-92. ISSN: 0008-8846

Khatib, J.M., Mangat, P.S., and Wright, L. (2008) Sulphate resistance of blended binders containing FGD waste. Construction Materials Journal - Proceedings of the 
Institution of Civil Engineers (ICE), Vol. 161, Issue CM3, August 2008, pp. 119-128. ISNN 1747-650X doi: 10.1680/coma.2008.161.3.119

Khatib, J.M., Mangat, P.S., and Wright, L. (2013a) Early Age Porosity and Pore Size Distribution of Cement paste with Flue Gas Desulphurisation (FGD) Waste. Journal of Civil Engineering and Management, 19 (5), 622-627, Taylor \& Francis, ISSN 1392-3730 print/ISSN 1822-3605 online, doi: 10.3846/13923730.2013.793609

Khatib, J.M., Mangat, P.S., and Wright, L. (2014) Pore Size Distribution of Cement pastes Containing Fly Ash-Gypsum Blends Cured for 7 Days. Korean Society of Civil Engineering (KSCE) Journal, 18 (4), 1091-1096. doi: 10.1007/s12205-014-0136-8 Online ISSN: 1976-3808; Print ISSN: 1226-7988

Khatib, J.M., Wright, L., and Mangat, P.S. (2013b) Effect of fly ash-gypsum blend on porosity and pore size distribution of cement pastes. Journal of Advances in Applied Ceramics, Structural, Functional and Bioceramics, 112 (4), 197-201, online, ISSN 17436753, DOI: 10.1179/1743676112Y.0000000032

Khatib, J.M., Wright, L., and Mangat, P.S. (2016) Mechanical and Physical Properties of Concrete Containing FGD Waste. Magazine of Concrete Research, Vol. 68, No. 11, pp 550-560, doi: 10.1680/macr.15.00092.

Kurdi, A., Awad, A., Kassim, M., and El-Zaafraney, M. (1996) Properties and usage of cement kiln dust in concrete. Alexandria Engineering Journal, 35 (5), 209-222.

Liu, A., Ren, F., Lin, W.Y. and Wang, J.Y. (2015). "A review of municipal solid waste environmental standards with a focus on incinerator residues." International Journal of Sustainable Built Environment, 4(2), pp.165-188.

Li, X., Zhang, C., Li, Y. and Zhi, Q. (2016). "The status of municipal solid waste incineration (MSWI) in China and its clean development." Energy Procedia, 104, pp.498-503.

Martys, N.S. and Ferraris, C.F. (1997). "Capillary transport in mortars and concrete." Cement and Concrete Research, 27(5), 747-760.

Mangat, P.S., Khatib, J.M., and Wright, L. (2006) Optimum Utilisation of Flue Gas Desulphurisation (FGD) Waste in Blended Binder for Concrete. Construction Materials Journal - Proceedings of the Institution of Civil Engineers, 1 (2), pp 6068, August 2006. ISNN 1747-650X

Menadi, B., Kenai, S., and Khatib, J.M. (2014) Fracture behaviour of concrete containing limestone fines. Proceedings of the ICE; Construction Materials Journal ,167 (3), 162-170, June 2014, Paper 1200041 DOI: 10.1680/coma.12.00041.

Morales-Hernandez, B., Khatib, J.M., and Gardiner, P. (2005) Use of Municipal Solid Waste Incineration Bottom Ash (MSWI-BA) in Cement Mortar. Proceedings of the 1 st Global Slag Conference - From Problem to Opportunity, Dusseldorf, Germany, 14-15 November 2005, pp. 210-218. ttp://www.propubs.com/gsc/gs05reviewed.html

Nikbin, I.M., Rahimi, S., Allahyari, H. and Damadi, M. (2016). "A comprehensive analytical study on the mechanical properties of concrete containing waste bottom ash as natural aggregate replacement." Construction and Building Materials, 121, pp.746-759.

Ornebjerg, H., Franck, J., Lamers, F., Angotti, F., Morin, R. and Brunner, M. (2006). "Management of bottom ash from WTE plants." ISWA-WG Thermal Treatment.

Owens, P.L., Boarder, R., and Khatib, J.M. (2016). Sustainability of lightweight aggregates manufactured from waste clay for reducing the carbon footprint of concrete. In: Khatib, J.M. (ed.), Sustainability of Construction Materials. 2nd edition. Elsevier, pp. 209-246, ISBN 978-0-08-100995-6

Rehman, S.K.U., Ibrahim, Z., Memon, S.A. and Jameel, M. (2016). "Nondestructive test methods for concrete bridges: A review." Construction and Building Materials, 107, $58-86$ 
Salvo, M., Rizzo, S., Caldirola, M., Novajra, G., Canonico, F., Bianchi, M. and Ferraris, M. (2015). "Biomass ash as supplementary cementitious material (SCM)." Advances in Applied Ceramics, 114(sup1), pp. S3-S10.

Tang, P. (2017). "Municipal solid waste incineration (MSWI) bottom ash-from waste to value: characterization, treatments and application." Bouwstenen, 234.

Tasdemir, C. (2003). "Combined effects of mineral admixtures and curing conditions on the sorptivity coefficient of concrete." Cement and concrete research, 33(10), pp.16371642.

Wright, L. and Khatib, J.M. (2016) Sustainability of desulphurised waste materials in construction. In: Khatib, J.M. (ed.), Sustainability of Construction Materials, 2nd edition. Elsevier, pp. 685-720, ISBN 978-0-08-100995-6

Zhansaya, N., Negim, E.S.M., Rauash, A.M., Khatib, J.M., Mun, G.A., and Williams, C. (2014) Effect of $\mathrm{pH}$ on the physico-mechanical properties and miscibility of MC/PAA blends. Carbohydrate Polymers Journal, 101, 415-422, Elsevier, http://dx.doi.org/10.1016/j.carbpol.2013.09.047 